Research, Society and Development, v. 9, n. 3, e135932478, 2020

(CC BY 4.0) | ISSN 2525-3409 | DOI: http://dx.doi.org/10.33448/rsd-v9i3.2478

\title{
Caracterização das barragens de rejeitos de mineração no Brasil
}

Characterization of Brazil mine tailings dams

Caracterización de presas de relaves mineros en Brasil

Recebido: 22/12/2019 | Revisado: 27/01/2020 | Aceito: 16/02/2020 | Publicado: 29/02/2020

Gabriel Jhonatas Natalino Barcelos

ORCID: https://orcid.org/0000-0002-8228-1111

Fundação Comunitária de Ensino Superior de Itabira, Brasil

E-mail: gabriel_barcelos@outlook.com.br

José Rafael Duarte Lage

ORCID: https://orcid.org/0000-0002-3373-5797

Fundação Comunitária de Ensino Superior de Itabira, Brasil

E-mail: joserafael13@gmail.com

Juni Silveira Cordeiro

ORCID: https://orcid.org/0000-0001-9371-8385

Fundação Comunitária de Ensino Superior de Itabira, Brasil

E-mail: juni.cordeiro@funcesi.br

\section{Resumo}

Os métodos de beneficiamento utilizados pelas mineradoras brasileiras fazem com que o país tenha uma quantidade significativa de barragens. Neste contexto, este trabalho objetivou caracterizar essas estruturas de acordo com a altura, o volume, a categoria de risco e os danos ambientais. Para a realização deste estudo, utilizou-se uma abordagem quantitativa e análise documental, que consistiu no exame do inventário de barragens referente ao ano de 2019, disponibilizado pela Agência Nacional de Mineração. Os resultados obtidos indicam que no Brasil existem 769 barragens cadastradas, sendo que a maioria destas estão localizadas nos estados de Minas Gerais (45,6\%) e no Pará (13,5\%). Notou-se com relação ao volume e altura que as barragens de pequeno porte são a maioria, correspondendo, respectivamente, a 74,2\% e $64,5 \%$ das estruturas cadastradas. Além disso, observou-se que a maior parte dos rejeitos depositados nas barragens são provenientes da mineração de argila e ou/areia. Notou-se que $53,4 \%$ das barragens foram construídas em etapa única, entretanto, ressalta-se que 81 barragens não possuem indicação do método construtivo empregado. Em relação à categoria de risco e dano potencial associado, 217 barragens estão inseridas na classe "B" e 44,7\% não possuem 
essa informação. É necessário que as mineradoras realizem com frequência o monitoramento dessas estruturas, juntamente com inspeções técnicas a fim de diminuir o risco de ruptura e aumentar a segurança das barragens.

Palavras-chave: Barragem de rejeitos; Beneficiamento mineral; Categoria de risco; Danos ambientais.

\begin{abstract}
The beneficiation methods used by Brazilian mining companies make the country have a significant number of dams. In this context, this work aimed to characterize these structures according to height, volume, risk category and environmental damage. For this study, we used a quantitative approach and document analysis, which consisted of examining the dam inventory for the year 2019, provided by the National Mining Agency. The results obtained indicate that in Brazil there are 769 registered dams, most of which are in the states of Minas Gerais (45.6\%) and Pará (13.5\%). It was noted about volume and height that small dams are the majority, corresponding, respectively, to $74.2 \%$ and $64.5 \%$ of the registered structures. In addition, it was observed that most of the tailings deposited in the dams come from clay and / or sand mining. It was noted that $53.4 \%$ of the dams were built in a single stage, however, it is noteworthy that 81 dams have no indication of the construction method employed. Regarding the risk category and associated potential damage, 217 dams are included in class "B" and $44.7 \%$ do not have this information. Miners are often required to monitor these structures along with technical inspections to reduce the risk of rupture and increase dam safety.
\end{abstract}

Keywords: Tailings dam; Mineral processing; Risk category; Environmental damage.

\title{
Resumen
}

Los métodos de beneficio utilizados por las compañías mineras brasileñas hacen que el país tenga una cantidad significativa de represas. En este contexto, este trabajo tuvo como objetivo caracterizar estas estructuras de acuerdo con la altura, el volumen, la categoría de riesgo y el daño ambiental. Para este estudio, utilizamos un enfoque cuantitativo y un análisis de documentos, que consistió en examinar el inventario de presas para el año 2019, proporcionado por la Agencia Nacional de Minería. Los resultados indican que en Brasil hay 769 presas registradas, la mayoría de las cuales se encuentran en los estados de Minas Gerais $(45,6 \%$ ) y Pará $(13,5 \%)$. Se observó con respecto al volumen y la altura que las presas pequeñas son la mayoría, que corresponden, respectivamente, al 74,2\% y al 64,5\% de las estructuras registradas. Además, se observó que la mayoría de los relaves depositados en las presas provienen de la 
extracción de arcilla y / o arena. Se observó que el 53.4\% de las represas se construyeron en una sola etapa, sin embargo, es de destacar que 81 represas no tienen indicación del método de construcción empleado. Con respecto a la categoría de riesgo y el daño potencial asociado, se incluyen 217 represas en la clase "B" y el 44.7\% no tiene esta información. Los mineros a menudo deben monitorear estas estructuras junto con inspecciones técnicas para reducir el riesgo de ruptura y aumentar la seguridad de la presa.

Palabras clave: Presa de relaves; Procesamiento de minerales; Categoría de riesgo; Daño ambiental.

\section{Introdução}

O Brasil é um país rico em recursos naturais com expressivas reservas de minérios como ouro, manganês, cobre, alumínio, níquel, nióbio e ferro, despertando o interesse de mineradoras que visam explotar esses recursos, movimentando a economia do país.

$\mathrm{Na}$ atividade de mineração existem três fases que estão intimamente relacionadas: a lavra, as operações de beneficiamento e o sistema de disposição de rejeitos, sendo que este último representa um desafio para as mineradoras, dada a dificuldade de áreas adequadas para a disposição dessas substâncias e por ser fonte de degradação ambiental e de impactos negativos paisagísticos (Araújo, 2006).

De acordo com a Vale (2018), as barragens de rejeito são estruturas utilizadas como reservatórios para contenção e acumulação de substâncias líquidas ou de misturas de líquidos e sólidos provenientes do processo de beneficiamento de minérios. Essas estruturas são consideradas o meio economicamente mais viável para a disposição de rejeitos, uma vez que são construídas em menor tempo, podendo utilizar para isso o próprio material a ser disposto (Soares, 2010).

Com relação aos aspectos normativos, no Brasil, a Lei $n^{\circ}$ 12.334/2010 estabeleceu a Política Nacional de Segurança de Barragens (PNSB) aplicada às barragens destinadas à acumulação de água para quaisquer usos, à disposição final ou temporária de rejeitos e à acumulação de resíduos industriais que apresentem: altura do maciço maior ou igual a 15 metros; e/ou capacidade total do reservatório maior ou igual três milhões de metros cúbicos; e/ou reservatório que contenha resíduos perigosos; e/ou categoria de dano potencial associado médio ou alto (Brasil, 2010).

Contudo, há diversos registros de acidentes com essas estruturas no Brasil, podendo ser destacados o rompimento da barragem de rejeito de mineração de bauxita em Barcarena no 
(PA), no ano de 2009, que resultou no transbordamento de canais; o rompimento da Barragem de Fundão, em Mariana (MG), em 2015, que resultou em 17 vítimas fatais e 2 pessoas desaparecidas e; mais recentemente, em janeiro de 2019, o rompimento da Barragem I, localizada em Brumadinho (MG), que além de liberar 12 milhões de metros cúbicos de rejeitos para o sistema fluvial a jusante, resultou em 270 vítimas entre mortos e desaparecidos (WiseUranium, 2019).

Dessa forma, este artigo objetivou caracterizar o risco e o dano potencial associado às barragens de rejeitos provenientes da mineração no Brasil cadastradas pela Agência Nacional de Mineração (ANM). Além disso, buscou-se associar a altura e o volume dessas estruturas com o tipo de minério explotado e o método de alteamento empregado.

\section{Classificação das barragens}

De acordo com a PNSB as barragens são classificadas por categoria de risco, por dano potencial associado e pelo seu volume, com base em critérios gerais estabelecidos pelo Conselho Nacional de Recursos Hídricos - CNRH (Brasil, 2010).

A Agência Nacional de Mineração (ANM), é a responsável pela classificação das barragens de mineração de acordo com a categoria de risco e o dano potencial associado, que podem ser agrupadas nas classes A, B, C, D, E (Brasil, 2017), como pode ser observado no Quadro 1.

Quadro 1 - Classificação das barragens de mineração de acordo com a categoria de risco e o dano potencial associado

\begin{tabular}{|c|c|c|c|}
\hline & \multicolumn{3}{|c|}{ Dano Potencial Associado } \\
\hline Categoria de Risco & Alto & Médio & Baixo \\
\hline Alto & A & B & C \\
\hline Médio & B & C & D \\
\hline Baixo & B & C & E \\
\hline
\end{tabular}

Fonte: Brasil, 2017.

A PNSB classifica as categorias de risco em alto, médio ou baixo, a partir de fatores associados às características técnicas das estruturas, ao grau de conservação do empreendimento e seu plano de segurança. Já a classificação do dano potencial associado à barragem está relacionada às perdas de vidas humanas e impactos econômicos, sociais e ambientais decorrentes de ruptura da barragem (Brasil, 2010). 
Destaca-se que, de acordo com a Portaria da ANM nº 70.389/2017 é obrigação do empreendedor elaborar o mapa de inundação para auxílio da classificação quanto ao dano potencial associado, que deve representar o cenário atual da barragem, em conformidade com sua cota licenciada. Além disso o mapa de inundação deve ser elaborado com base topográficas atualizadas para representação da região a jusante dessas estruturas (Brasil, 2017).

Cabe ao empreendedor instalar nas áreas que correspondem às Zonas de Alto Salvamento (ZAS) mecanismos como sirenes e outras formas que possibilitem alertar a população sobre possíveis situações de emergência, além de elaborar o plano de contingência e treinamento da população potencialmente afetada (Brasil, 2017).

\section{Metodologia}

Esta pesquisa teve uma abordagem quantitativa. De acordo com Botelho e Cruz (2013), a abordagem quantitativa tem como referência a análise de dados estatísticos, transformando informações em números, com objetivo de analisar e interpretar eventos que ocorreram ou que possam ocorrer através de análises estatísticas. Essa abordagem mostrou-se adequada à pesquisa uma vez que foram analisados o número de barragens por estado, categoria de risco e dano potencial das barragens de mineração situadas no Brasil.

Esta pesquisa foi do tipo descritiva, que segundo Gerhardt e Silveira (2009), tem como objetivo caracterizar, descrever, analisar e interpretar os dados obtidos sem a interferência do pesquisador. Assim, a pesquisa descritiva foi utilizada neste trabalho para descrever e identificar a categoria de risco e o dano potencial das barragens de mineração situadas no Brasil.

De acordo com Prodanov e Freitas (2013), a amostra é uma parte de uma população ou do universo, que será amostrado. Dessa forma, a amostra desta pesquisa correspondeu às 769 barragens de contenção de minérios situadas no Brasil, mantidas pelo Sistema Nacional de Informações Sobre Segurança de Barragens e cadastradas pela ANM.

O instrumento de coleta de dados utilizado nesta pesquisa foi a análise documental que, segundo Pimentel (2001), corresponde a organização e compreensão dos documentos necessários para realização de uma pesquisa. Dessa forma, utilizou-se a planilha disponibilizada pela ANM (2019) para análise das informações tais como altura, volume, tipo de minério, potencial de dano e categoria de risco das barragens de rejeito de mineração.

Os dados obtidos foram tratados por meio da estatística descritiva. De acordo com Perovano (2016), a estatística descritiva tem como objetivo reunir as informações coletadas de 
Research, Society and Development, v. 9, n. 3, e135932478, 2020

(CC BY 4.0) | ISSN 2525-3409 | DOI: http://dx.doi.org/10.33448/rsd-v9i3.2478

forma clara e objetiva, para que a análise de dados seja eficiente. Assim, a estatística descritiva foi utilizada nesta pesquisa na elaboração de gráficos, tabelas e cálculo de porcentagens.

\section{Resultados e discussão}

Os minérios raramente são encontrados em sua forma pura na natureza, deste modo, precisam ser tratados pelo processo de beneficiamento. Entretanto, neste processo são gerados além do produto, os rejeitos, que não possuem valor econômico e normalmente são depositados em barragens (Chaves, 2002).

Há no Brasil 769 barragens de contenção de rejeitos provenientes da mineração (ANM, 2019). Com relação à localização destas estruturas, notou-se que os estados de Minas Gerais (MG) e Pará (PA) apresentam, juntos, 59\% deste total (Figura 1).

Figura 1 - Número de barragens por estados no Brasil no ano de 2019.

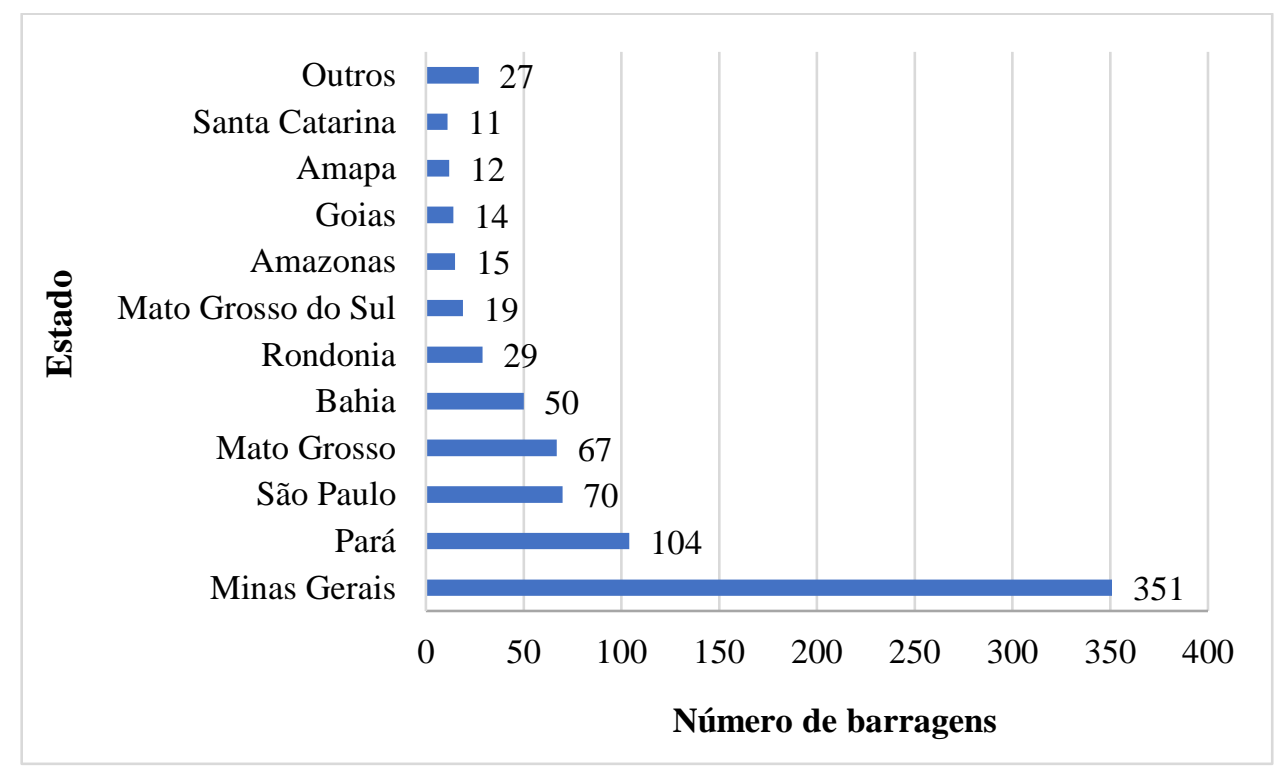

Fonte: Dados de pesquisa, 2019.

Destaca-se que os estados do Ceará, Rio Grande do Norte, Pernambuco, Alagoas, Acre, Roraima, além do Distrito Federal, não possuem barragens de mineração cadastradas na ANM. Já os Estados do Paraná e Rio Grande do Sul possuem apenas 5 barragens; Rio de Janeiro e Sergipe possuem 3 estruturas cada um; Piauí, Tocantins, Espírito Santo, Maranhão e Paraíba, apresentam apenas uma barragem cada um e estão agrupadas na categoria "outros" na Figura 1. 
Para Ribeiro e Silva (2018), os estados de Minas Gerais e Pará são os dois principais produtores de minérios do Brasil, dado o número significativo de reservas minerais, sobretudo de minério de ferro.

Com relação ao tipo de substância depositada nessas estruturas nota-se que as principais correspondem aos rejeitos originados da mineração de argila e ou/ areia e ou/ cascalho, observados em $30 \%$ das estruturas; rejeitos de minério de ferro, depositados em 29,9\% das barragens e rejeitos de minério de ouro, verificado em $10 \%$ das estruturas. Destaca-se que os resíduos de substâncias lavradas como bauxita, manganês, nióbio e níquel foram observadas em menos de $2 \%$ das estruturas, sendo classificadas como "outros" na Figura 2.

Figura 2 - Número de barragens por tipo de substância

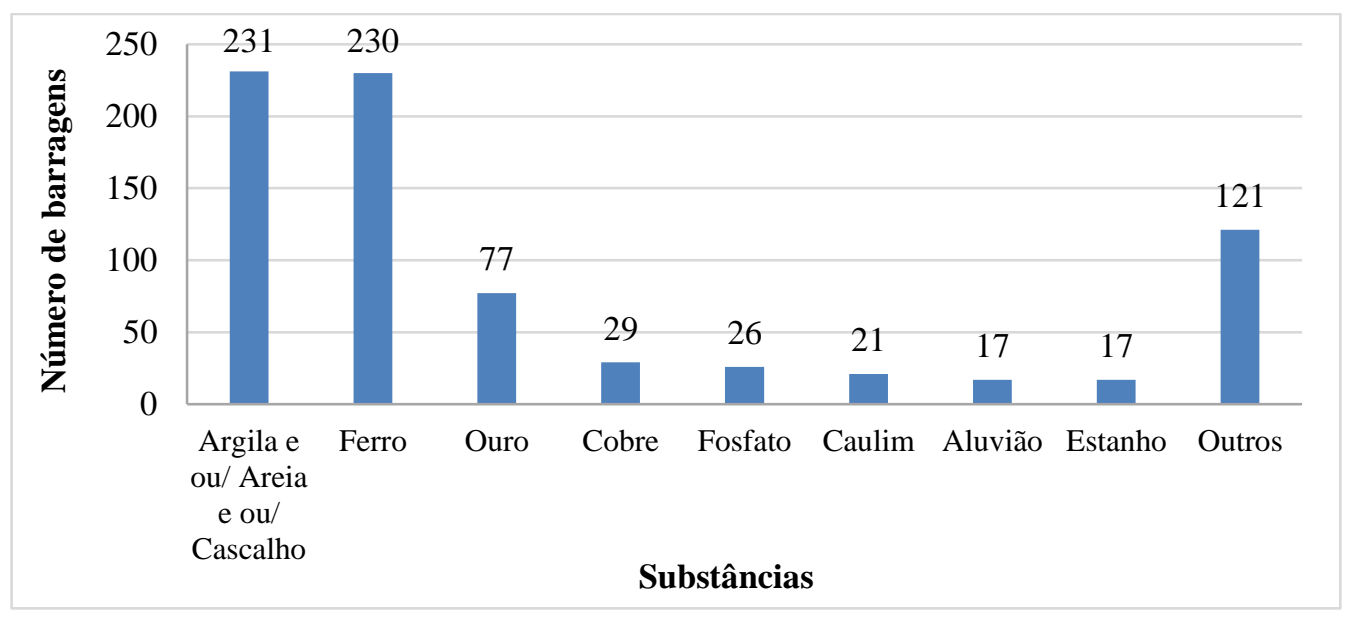

Fonte: Dados de pesquisa, 2019.

Quando observadas as substâncias depositadas nas barragens por estado, verifica-se que em Minas Gerais, 54,4\% dessas estruturas são utilizadas para contenção de rejeitos provenientes do beneficiamento do minério de ferro; 22,5\% armazenam os rejeitos da mineração de argila e ou/ areia e ou/ cascalho e 23,1\% correspondem à mineração de outras substâncias, tais como ouro, zinco e manganês.

Já no Estado do Pará, 34,6\% são estruturas de contenção de rejeitos da mineração de argila e ou/ areia e ou/ cascalho; 16,3\% dessas estruturas armazenam os rejeitos da mineração de caulim, 15,4\% barragens são utilizadas para a contenção de rejeitos de minério de ferro e, por fim, 33,7\% contém os rejeitos de outras atividades minerárias, como explotação de bauxita, cobre, manganês, níquel e ouro.

Uma característica relevante na caracterização das barragens corresponde à sua altura, que pode ser definida como o desnível entre a cota do pé do talude de jusante e a crista da 
(CC BY 4.0) | ISSN 2525-3409 | DOI: http://dx.doi.org/10.33448/rsd-v9i3.2478

barragem (topo), sendo este um dos parâmetros de classificação dessas estruturas (Minas Gerais, 2002). Além disso, esse é um fator relevante quanto à estabilidade dessas estruturas, uma vez que quanto maior a altura maior será a pressão exercida na base e na fundação (Pereira, 2016).

Wallingford et al. (2019) definem que as barragens de pequeno porte são caracterizadas por alturas de até $15 \mathrm{~m}$, aquelas consideradas de médio porte possuem altura variando de $15 \mathrm{a}$ $30 \mathrm{~m}$, enquanto as barragens de grande porte possuem altura superior a $30 \mathrm{~m}$.

Desta forma, a Figura 3A exibe o intervalo de altura das barragens brasileiras, sendo possível notar que a maioria das estruturas $(64,5 \%)$, pode ser considerada de pequeno porte, $19,2 \%$ correspondem às barragens de médio porte, enquanto $16,3 \%$ representam estruturas de grande porte.

Figura 3 - Classificação das barragens de rejeitos situadas no Brasil quanto (A) altura e (B) volume.

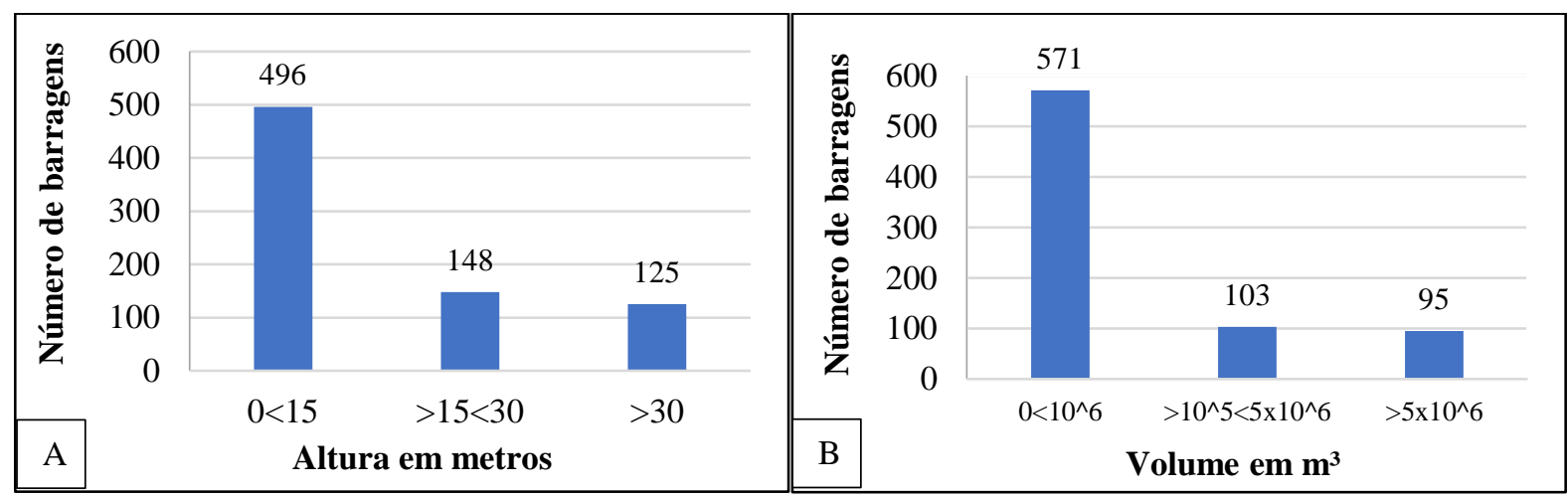

Fonte: Dados da pesquisa, 2019.

Destaca-se que no Estado de Minas Gerais, 51,3\% das barragens podem ser consideradas de pequeno porte; $20,5 \%$ correspondem a estruturas de médio porte e $28,2 \%$ podem ser consideradas barragens de grande porte. Já o Estado do Pará possui 68,3\% barragens classificadas como pequeno porte; $23,1 \%$ das barragens são consideradas como médio porte, enquanto $8,6 \%$ dessas estruturas podem ser classificadas como de grande porte.

Considerando as barragens de grande porte em relação à altura, nota-se que 79,2\% dessas estão localizadas no Estado de Minas Gerais, sendo que 65,7\% das estruturas são utilizadas para disposição dos rejeitos da mineração de ferro; $13,1 \%$ são utilizadas para armazenamento de rejeitos da mineração de ouro, $8,1 \%$ dos rejeitos provenientes da mineração de fosfato e, por fim, demais substâncias (tais como aluvião, bauxita, calcário, níquel, zinco, pegmatito, xisto) correspondem a 13,2\% das barragens. 
O estado do Pará possui 7,2\% das barragens consideradas de grande porte com relação à altura, sendo que 33,4\% dessas estruturas são utilizadas para contenção dos rejeitos da mineração de ferro, 22,2\% armazenam os rejeitos da mineração de cobre e bauxita, enquanto $11,1 \%$ das estruturas são destinadas à disposição dos rejeitos da mineração de manganês e caulim.

De acordo com Robertson (2017), as barragens têm apresentado a tendência de dobrar a sua altura a cada 30 anos. Além disso, segundo Verol (2010), as barragens consideradas altas geram maiores preocupações e cuidados devido a proporção dos danos causados em caso de um possível colapso, requerendo, dessa forma, uma maior atenção.

O volume, bem como altura do maciço e população a jusante das estruturas, é um importante parâmetro que deve ser considerado na classificação das barragens, uma vez que estes implicam em um alto dano ambiental, social, econômico e perdas de vidas (Brasil, 2010). De acordo com Wallingford (2019), as barragens consideradas de pequeno porte apresentam volume de até 1 milhão de metros cúbicos $\left(\mathrm{m}^{3}\right)$; as barragens de médio porte são aquelas que possuem de 1 a 5 milhões de $\mathrm{m}^{3}$, e aquelas consideradas de grande porte apresentam volume superior a 5 milhões de $\mathrm{m}^{3}$.

Nota-se na Figura 3B que no Brasil as barragens de pequeno porte em relação ao volume representam $74,2 \%$ das estruturas, aquelas consideradas de médio porte correspondem a 13,4\%, e de grande porte representam $12,4 \%$ das estruturas.

Destaca-se que dentre as barragens consideradas de grande porte, $35,8 \%$ são utilizadas para disposição de rejeitos de minério de ferro, $14,7 \%$ para os rejeitos da mineração de argila e areia, 11,6\% armazenam os rejeitos da mineração de ouro.

Ainda com relação ao volume, observa-se que no Estado de Minas Gerais 44,8\% dessas estruturas são consideradas de pequeno porte; 42,7\% são estruturas consideradas de médio porte; já aquelas consideradas de grande porte representam a 14,5\% das estruturas. O estado do Pará possui $22,1 \%$ das barragens consideradas de pequeno porte; $21,2 \%$ de médio porte, enquanto $56,7 \%$ das barragens são consideradas de grande porte.

Os métodos comumente utilizados na construção de barragens são a montante, a jusante e de linha de centro, sendo que a diferença entre eles está associada à forma de alteamento dessas estruturas com relação ao estágio inicial do dique de contenção (Sabbo, Assis e Berterquini, 2017). Faz-se importante salientar que 10,5\% das barragens brasileiras não possuem método construtivo indicado (ANM, 2019). 
De acordo com Valerius (2014) no método de etapa única uma barragem não recebe alteamento, sendo muito utilizado para a retenção de água. Este método foi utilizado em 53,4\% das barragens brasileiras.

O método a montante é a técnica mais antiga, simples e econômica para a construção de barragens de rejeitos quando comparado aos demais. Contudo, apresenta menor segurança, uma vez que a barragem é construída sobre materiais que já foram depositados, que podem não estar consolidados, aumentando o risco de ruptura dessas estruturas (Araújo, 2006). Destaca-se que 11,3\% das barragens brasileiras foram alteadas por esse método.

De acordo com Soares (2010) o método de construção a jusante possui um alto custo e o processo de alteamento é lento, sendo necessária a movimentação de grande quantidade de material. No Brasil, 19,8\% das barragens foram construídas utilizando esse método.

O método linha de centro é uma versão intermediária dos métodos a montante e jusante, e visa explorar as vantagens de cada método e reduzir o fator negativo destes. Dessa forma, o método de linha de centro apresenta maior estabilidade quando comparado às barragens a montante e necessita de um menor volume de material para construção do que as barragens a jusante (Araújo, 2006). Destaca-se que 4,9\% das barragens foram alteadas por esse método.

Quando confrontado o método de alteamento das estruturas por porte considerando o volume armazenado, nota-se na Tabela 1 que as barragens consideradas de pequeno porte foram, em sua maioria, alteadas pelo método de etapa única. Já as barragens consideradas de médio porte foram em sua maioria $(39,8 \%)$ alteadas pelo método a jusante, considerada a técnica mais segura. Salienta-se que a maioria das barragens de grande porte $(32,6 \%)$ foram alteadas pelo método a montante, considerado o mais inseguro e que apresenta menor estabilidade.

Tabela 1 - Método de alteamento das barragens brasileiras por porte considerando o volume no ano de 2019

\begin{tabular}{ccccc}
\hline \multirow{2}{*}{ Porte } & \multicolumn{4}{c}{ Alteamento (\%) } \\
\cline { 2 - 5 } & Etapa única & Jusante & Montante & Linha de centro \\
\hline Pequeno & 63.4 & 14,5 & 5,6 & 2,5 \\
Médio & 28,2 & 39,8 & 23,3 & 8,7 \\
Grande & 21,1 & 30,5 & 32,6 & 15,8 \\
\hline
\end{tabular}

Fonte Dados de pesquisa, 2019

Ressalta-se que, de acordo com a Resolução da ANM n 13/2019 devido aos acidentes ocorridos no Estado de Minas Gerais, com Barragem B1 em 2014, localizada no município de 
Itabirito, da Barragem de Fundão em 2015, na cidade de Mariana e da Barragem BI em 2019, em Brumadinho, foi proibida a utilização do alteamento pelo método a montante em todo o país, visto que todas essas estruturas foram construídas por este método. Além disso, as estruturas remanescentes, alteadas por este método terão que ser descomissionadas ou descaracterizadas até o dia 15 de setembro de 2027 (Brasil, 2019).

As barragens de rejeito são a forma mais viável economicamente para as empresas mineradoras, porém implicam em riscos para a população e ao meio ambiente, independente do seu método de construção.

Quando considerados os riscos associados à uma barragem, Galo (2017) destaca que para gerenciá-los é necessário identificar, analisar e realizar o monitoramento constante da estrutura, buscando a eliminação ou a diminuição do problema.

De modo geral, os riscos que uma barragem possui estão associados às diversas situações como condições do reservatório, sua forma de operação, suas falhas e ao número de pessoas que residem a jusante da estrutura (Ancold, 2003 apud Galo, 2017). Além destas situações, podem ser destacadas as condições implantadas no momento da construção de uma barragem e sua gestão (Minas Gerais, 2002).

Considerando as 769 barragens brasileiras, 0,3\% destas são classificadas como de alto risco; $7,9 \%$ possuem risco médio; $46,9 \%$ são consideradas como de risco baixo e $44,8 \%$ dessas barragens não apresentam informações quanto a esse aspecto. Destaca-se que a região que apresentou maior número de barragens com a categoria de risco alto, foi a região |Sudeste, sendo que $100 \%$ dessas estruturas estão localizadas no Estado de Minas Gerais, no município de Rio Acima.

Nodari e Guerra (2001), ressaltam a importância de se conhecer os riscos e elaborar um plano para minimizar os impactos referentes a ruptura de barragens. Neste contexto, destaca-se que alguns danos ambientais causados pelo colapso de uma barragem podem ser considerados irreversíveis (Minas Gerais, 2002).

No Brasil, 28,4\% das barragens possuem um alto dano potencial em caso de um rompimento, $20,3 \%$ possuem médio dano potencial e $6,4 \%$ possuem baixo dano potencial. No entanto, 44,6\% das barragens não possuem informações sobre o dano potencial associado.

A região Sudeste se destaca com relação à presença de barragens com alto dano potencial (69,9\% das estruturas) e médio dano potencial (37,6\%). De acordo com Lacaz, Porto e Pinheiro (2016), esses danos podem ser minimizados com o investimento em tecnologias mais seguras por parte das empresas do setor, aliado à existência de uma legislação com ênfase no meio ambiente, saúde e segurança da população. 
Uma barragem é classificada de acordo com a sua periculosidade (características técnicas das barragens), vulnerabilidade (situação atual da estrutura e sua vulnerabilidade à uma ruptura) e importância estratégica (dimensão dos possíveis impactos) (Duarte, 2008). Assim, a ANM classifica as barragens de mineração de acordo com o dano potencial associado e categoria de risco nas classes A, B, C, D, E (Brasil, 2017).

Verifica-se que 28,2\% das barragens são classificadas como "B"; 20,4\% são classificadas como "C"; $5 \%$ são associadas à classe "E", 1,2\% são classificadas como "D", e apenas $0,3 \%$ pertencem à classe "A", que corresponde àquela que apresenta o maior risco de se romper e causar danos ambientais. No entanto, ressalta-se que 44,7\% das barragens não possuem este tipo de informação (Figura 4).

Figura 4 - Classificação das categorias de risco e dano potencial associado das barragens brasileiras no ano de 2019

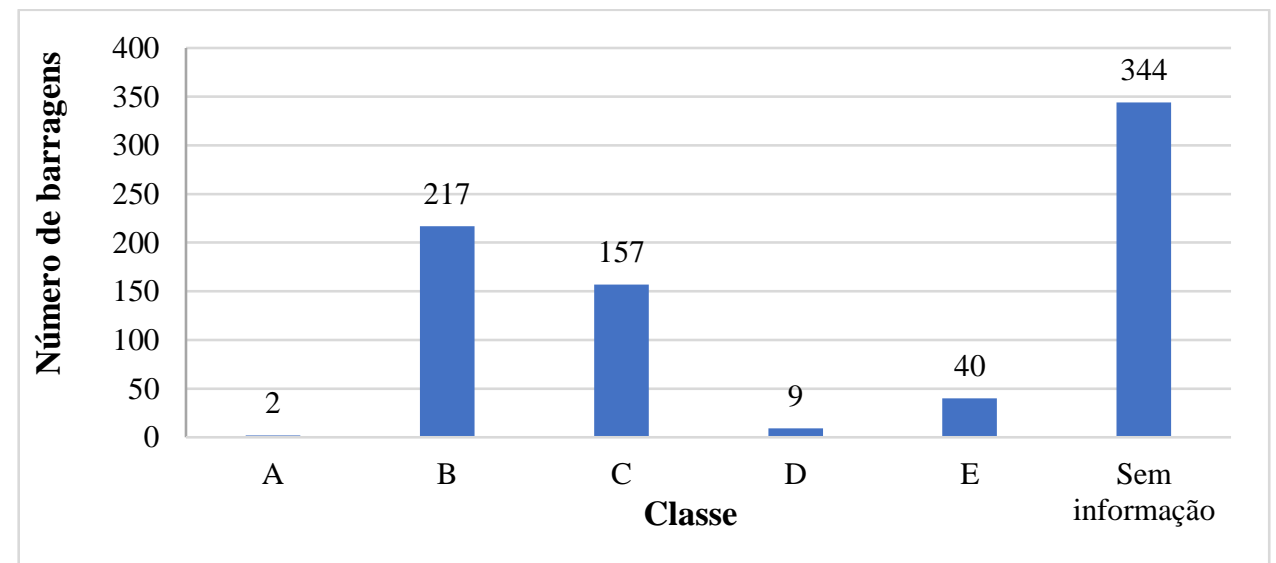

Fonte: Dados de pesquisa, 2019.

As barragens de rejeitos precisam de constante monitoramento e acompanhamento, uma vez que independentemente do método de alteamento, representam um risco à população e ao meio ambiente. Ressalta-se que acidentes ocorridos com barragens tendem a ter impactos negativos imensuráveis nos âmbitos social, econômico e ambiental, por isso se faz importante que as mineradoras invistam em métodos de disposição dos seus rejeitos mais seguros.

\section{Considerações finais}

O Brasil é um país rico em recursos minerais que possuem um papel relevante na economia do país. Entretanto, estes recursos não estão disponíveis em sua forma pura na natureza, fazendo-se necessário o beneficiamento das substâncias, que por vez gera rejeitos, comumente depositados em barragens de contenção. 
Assim, esta pesquisa objetivou caracterizar a altura, volume, categoria de risco, dano potencial das barragens de contenção provenientes da mineração situadas no Brasil cadastradas na ANM no ano de 2019.

Notou-se que a maioria dessas estruturas estão localizadas nos estados de Minas Gerais e Pará. Neste sentido, ressalta-se que estes Estados são os dois maiores produtores de minerais do país, o que pode justificar uma quantidade expressiva de barragens.

Considerando a altura dessas estruturas, observou-se que a maioria das barragens situadas no Brasil podem ser consideradas de pequeno porte, sugerindo que podem estar no início de sua vida útil.

Quanto ao volume das barragens, notou-se que a maioria das estruturas pode ser considerada de pequeno porte. Entretanto, verificou-se que os estados de Minas Gerais e Pará possuem um número expressivo de barragens com volume de grande porte. Salienta-se, dessa forma, a importância do monitoramento dessas estruturas, uma vez que maiores volumes implicam em maiores riscos e possíveis danos associados no caso de um colapso.

Considerando o tipo de alteamento dessas estruturas observou-se que a maioria das barragens foram construídas pelo método de etapa única, contudo, muitas barragens não possuem indicação do método construtivo empregado. Ressalta-se que as barragens com maiores volumes foram alteadas pelo método a montante, um método economicamente mais viável, rápido, porém mais inseguro. Salienta-se que as barragens de Fundão em Mariana (MG), e B1 em Brumadinho tinham seu alteamento pelo método a montante.

Neste sentido destaca-se que a Resolução da ANM n ${ }^{\circ}$ 13/2019 proibiu a construção ou alteamento de barragem pelo método a montante em todo o território brasileiro. Além disso, os empreendimentos que possuem barragens alteadas por esta técnica estão obrigados a desativar e descomissionar essas estruturas até setembro de 2027.

Com relação ao tipo de substância depositada nessas estruturas notou-se que as mais representativas estão associadas às mineração de argila e ou/ areia e ou/ cascalho, seguida pelos rejeitos da mineração de ferro e ouro.

Considerando o risco dessas estruturas em caso de um possível colapso, notou-se que a maioria das barragens pode ser classificada como nível "baixo", porém existe um número significativo de barragens sem classificação. Ressalta-se que a avaliação do risco é relevante, pois possibilita o desenvolvimento de planos preventivos a fim de prevenir acidentes e/ou de minimizar impactos que essas estruturas possam causar.

Além disso, destaca-se que a maioria das barragens cadastradas possui um alto dano potencial em caso de um rompimento, entretanto, há uma quantidade expressiva de barragens 
sem essa classificação. A relevância desse parâmetro é atentar para a prevenção de um acidente, pois um colapso dessas estruturas pode acarretar a perda de vidas humanas e prejuízos imensuráveis nos âmbitos econômico, social e ambiental.

Com relação à classe das barragens situadas no Brasil, notou-se que a maioria pertence à classe "B". Ressalta-se que a classe "A", que corresponde às barragens consideradas como aquelas de maior risco e dano potencial, são minoria no Brasil. Contudo, a falta de monitoramento pode elevar os riscos de falhas, sendo assim, se faz relevante o acompanhamento dessas estruturas de forma a prevenir e corrigir possíveis anomalias a fim de evitar acidentes.

Ressalta-se a importância do cadastro dessas estruturas na ANM, pois por meio deste pode-se caracterizar as barragens situadas no Brasil por altura, volume categoria de risco, dano potencial. Dessa forma, salienta-se a importância do levantamento de todos os dados relacionados às estruturas, tais como aqueles referentes à classificação das barragens de rejeitos, o método construtivo, bem como a informação do seu estado de funcionamento atual. Neste sentido, recomenda-se a incorporação dessas informações no banco de dados para pesquisas futuras relacionadas a este tema.

\section{Referências}

Agência Nacional de Mineração (ANM). (2019). Classificação oficial ANM 19-02-2019. Acesso em 05 março de 2019 em http://www.anm.gov.br/assuntos/barragens/pasta-cadastronacional-de-barragens-de-mineracao/classificacao-oficial-anm/view.

Araújo, C. B. (2006). Contribuição ao estudo do comportamento de barragens de rejeito de mineração de ferro. Dissertação (Mestrado em Ciências em Engenharia Civil) - Universidade Federal do Rio de Janeiro, Rio de Janeiro.

Botelho, J. M. \& Cruz. V. A. G. (2013). Metodologia científica. São Paulo: Pearson Education do Brasil.

Brasil. Lei $n^{o}$ 12.334, de 20 de setembro de 2010. Estabelece a Política Nacional de Segurança de Barragens destinadas à acumulação de água para quaisquer usos, à disposição final ou temporária de rejeitos e à acumulação de resíduos industriais, cria o Sistema Nacional de Informações sobre Segurança de Barragens e altera a redação do art. 35 da Lei no 9.433, de 8 
de janeiro de 1997, e do art. 4o da Lei no 9.984, de 17 de julho de 2000. Acesso em 15 de março de 2019 em http://www.planalto.gov.br/ccivil_03/_ato2007-2010/2010/lei/112334.htm.

Brasil. Portaria $n^{\circ}$ 70.389, de 17 de maio de 2017. Cria o Cadastro Nacional de Barragens de Mineração, o Sistema Integrado de Gestão em Segurança de Barragens de Mineração e estabelece a periodicidade de execução ou atualização, a qualificação dos responsáveis técnicos, o conteúdo mínimo e o nível de detalhamento do Plano de Segurança da Barragem, das Inspeções de Segurança Regular e Especial, da Revisão Periódica de Segurança de Barragem e do Plano de Ação de Emergência para Barragens de Mineração, conforme art. $8^{\circ}$, $9^{\circ}, 10,11$ e 12 da Lei ${ }^{\circ} 12.334$ de 20 de setembro de 2010, que estabelece a Política Nacional de Segurança de Barragens - PNSB. Acesso em 15 de março de 2019, em http://www.dnpm.gov.br/portaria-dnpm-n-70389-de-17-de-maio-de-2017-seguranca-debarragens/view.

Brasil. Resolução $n^{\circ} 13$, de 8 de agosto de 2019. Estabelece medidas regulatórias objetivando assegurar a estabilidade de barragens de mineração, notadamente aquelas construídas ou alteadas pelo método denominado "a montante" ou por método declarado como desconhecido e dá outras providências. Acesso em 10 novembro de 2019 em http://www.in.gov.br/web/dou//resolucao-n-13-de-8-de-agosto-de-2019-210037027.

Chaves, A. P. (2002). Teoria e prática do tratamento de minérios. 2. ed. v.1. São Paulo: Signus Editora.

Galo, D. B. (2017). Análise de risco em barragens de rejeito com o uso de técnicas semiprobabilísticas de estabilidade de taludes - Um estudo de caso. Dissertação (Mestrado em Engenharia Ambiental Urbana) - Universidade Federal da Bahia, Salvador.

Gerhardt, T. E. \& Silveira, D. T. (2009). Métodos de pesquisa. Coordenado pela Universidade do Brasil - UAB/UFRGS e pelo Curso de Graduação Tecnológica - Planejamento e Gestão para Desenvolvimento Rural da SEAD/UFRGS. Porto Alegre: Editora da UFRGS.

Lacaz, F.A.C.; Porto, M.F.S. \& Pinheiro, T.M.M. (2006). Tragédias brasileiras contemporâneas: o caso do rompimento da barragem de rejeitos de Fundão/Samarco. Revista 
Brasileira de Saúde Ocupacional, São Paulo. Acesso em 18 de março de 2019 em https://www.redalyc.org/pdf/1005/100550852011.pdf.

Minas Gerais. Deliberação Normativa do Conselho Estadual de Política Ambiental (COPAM) $n^{o}$ 62, de 17 de dezembro de 2002. Dispõe sobre critérios de classificação de barragens de contenção de rejeitos, de resíduos e de reservatório de água em empreendimentos industriais e de mineração no Estado de Minas Gerais. Acesso em 15 setembro de 2019 em http://www.siam.mg.gov.br/sla/download.pdf?idNorma=5008.

Nodari, R. O. \& Guerra, M. P. (2001). Avaliação de riscos ambientais de plantas transgênicas. Brasília: Caderno de Ciências e Tecnologia, v. 18, p. 81-116.

Pereira, O. F. M. (2016). Análise da classificação de barragens de contenção de rejeitos no Brasil, quanto ao critério de categoria de risco. Dissertação (Mestrado Profissional em Uso Sustentável de Recursos Naturais em Regiões Tropicais). Instituto Tecnológico Vale Desenvolvimento Sustentável, Belém, Pará.

Perovano, D. G. (2016). Manual de metodologia da pesquisa científica. Curitiba: InterSaberes.

Pimentel, A. (2001). O método da análise documental: seu uso numa pesquisa historiográfica. Cadernos de Pesquisa, n. 114, p. 179-195, novembro/2001.

Prodanov, C. C. \& Freitas, E. C. (2013). Metodologia do trabalho científico: métodos e técnicas da pesquisa e do trabalho acadêmico. 2. ed. Novo Hamburgo, Feevale.

Ribeiro, J. C. J. \& Silva, L. C. N. (2018). A Mineração no Estado do Pará e as Barragens de Rejeito: o Paradigma Entre a Exploração e os Impactos Negativos Decorrentes. In: COSTA, Beatriz Souza (Org.). Anais... "V Congresso Internacional de Direito Ambiental e Desenvolvimento Sustentável: Pan-Amazônia - Integrar e Proteger" e do "I Congresso da Rede PanAmazônia”. Belo Horizonte: Dom Helder, p. 122-139.

Robertson, A. M. (2017). Managing risk: doing, checking and checking the checkers for tailings, water and waste management. Acesso em 23 de setembro de 2017 em http://www.eticaeventos.net.br/sngb2017/apresentacoes/sgbr/abertura.pdf. 
Sabbo, G. R.; Assis, M.M.G. \& Berterquini, A.B.T. (2017). Barragens de retenção de rejeitos de mineração. Revista Engenharia em Ação. UniToledo, v. 2, n. 1, Araçatuba.

Soares, L. (2010). Barragem de rejeitos. Rio de Janeiro: CETEM.

Vale. (2019). O que são barragens. Acesso em 10 de março de 2019 em http://www.vale.com/brasil/PT/aboutvale/servicos-para-comunidade/minasgerais/atualizacoes_brumadinho/Paginas/Entenda-as-barragens-da-Vale.aspx.

Valerius, M. B. (2014). Cadastro e análise do potencial de risco das barragens de rejeito de mineração do estado de Goiás. Dissertação (Mestrado em Geotecnia) - Universidade de Brasília, Brasília.

Verol, A. P. (2010). Simulação da propagação de onda decorrente de ruptura de barragem, considerando a planície de inundação associada a partir da utilização de um modelo pseudobidimensional. Dissertação de Mestrado (Programa de Pós-graduação em Engenharia Civil) Universidade Federal do Rio de Janeiro, Rio de Janeiro.

Wallingford, H. R; Roca, M.; Murphy, A.; Walker, L. \& Vallesl, S. (2019). A review of the risks posed by the failure of tailings dams. Reino Unido, n. 1, p. 5-59, 1 nov. 2019.

Wise Uranium Project. (2019). Chronology of major tailings dam failures. Acesso em 22 de março de 2019 em http://www.wise-uranium.org/.

\section{Porcentagem de contribuição de cada autor no manuscrito}

Gabriel Jhonatas Natalino Barcelos - 40\%

José Rafael Duarte Lage - $40 \%$

Juni Cordeiro - $20 \%$ 